\title{
IN SEARCH OF LOST SPACE
}

\section{The changing affordances of physical and virtual teaching spaces during the pandemic}

\section{Matteo Mazzamurro}

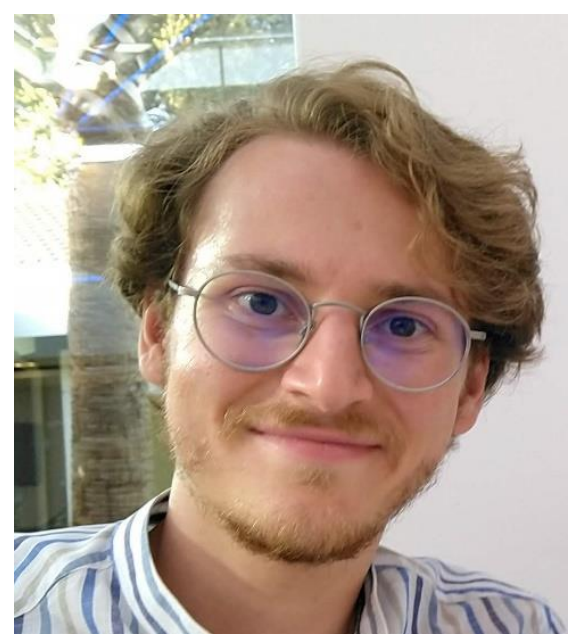

\author{
PhD Student, Department of Computer Science, \\ University of Warwick \\ Correspondence: matteo.mazzamurro@warwick.ac.uk \\ Twitter: @MattMazzamurro
}

I am a PhD Student in the Warwick Institute for the Science of Cities. I work on applications of spatial point processes and graph entropies to the study of the population dynamics of urban systems. Before joining Warwick, I studied Mathematics at Imperial College and worked as an IT Consultant in Milan, Geneva, and Bordeaux. Alongside research, I worked as a seminar tutor in Logic, Formal Methods, and other Mathematical modules in the Computer Science Department. I hold an Associate Fellowship HEA.

\begin{abstract}
In this reflection, I discuss the changing affordances of physical and virtual spaces in PGR seminar teaching during the Covid-19 pandemic. I start by reviewing how physical space has been conceptualised in the pedagogical literature in terms of its material aspects, affordances, and interactions with users. I then translate the above concepts to virtual teaching spaces. I discuss how the affordances of both physical and virtual spaces have evolved throughout the different stages of the pandemic, exemplifying the process through my personal experience of seminar teaching. I conclude with a personal reflection on the challenges and unexpectedly positive consequences of having to dynamically adapt one's pedagogy to changing affordances and constraints.
\end{abstract}

Keywords: Teaching Spaces; Online Teaching; Seminar Teaching; Covid-19 


\section{Physical and Virtual Space}

Physical space plays an active role in teaching and learning (Amedeo et al., 2008). It mediates and moderates both the teacher and learners' behaviour by facilitating the execution of certain activities and impeding others (Baepler et al., 2016). The objects in a physical learning space have certain "affordances": properties, actual or perceived, that determine how they will be used (Norman, 2002). The layout of the space also contributes to the perception of what is important for a learner (Exley \& Dennick, 2004) and, as such, it may either be an aid or an obstacle to effective learning. But the concept of physical space in teaching and learning is not limited to its material aspects, such as furniture and seating arrangements. It includes the interactions people have with and within the physical space, such as movement within the room and physical gestures (Leijon \& Lundgren, 2019). Every aspect of the design of physical learning spaces can, thus, be seen as "built pedagogy" (Monahan, 2002): a transposition in built form of educational theories, philosophies, and values (Rands \& Gansemer-Topf, 2017).

The proliferation in recent years of increasingly sophisticated virtual platforms that allow remote participation and reduce the need for physical presence has introduced another layer of complexity to the topic. What were originally conceived as tools to perform specific tasks have gradually transformed into true virtual "spaces", with their own material aspects, affordances and ways to shape interactions (White \& Le Cornu, 2011). Online learning platforms now include a large number of features. Some of these are explicitly meant to reproduce objects and properties of physical learning spaces, such as virtual whiteboards or live-streaming. Others provide opportunities which would not be possible in the physical realm, such as access to libraries of recordings, and alternative forms of peer engagement. The presence of such features, as well as the way they are managed, shape the perceived affordances of the virtual space, by either allowing or forbidding, or promoting or discouraging, certain actions. A great deal of interactions with and within virtual spaces are, as above, meant to mimic physical ones, such as virtually raising one's hand; but some are novel and do not have direct equivalents in the physical realm, such as modulating one's participation through turning off cameras and/or microphones at will.

Perhaps more subtly, virtual spaces interact with physical spaces in a non-trivial fashion. Scholars' opinions on the impact of introducing technology-mediated communication in teaching are mixed. Some criticise the distracting nature of virtual spaces and maintain that physical spaces in which one is physically surrounded by a supportive community, improve the student's academic performance and persistence (Parsons, 2016). Hybrid classes introducing technology such as live recordings and instant chats have been said to create complex and often undesirable dynamics involving the teacher, the students attending in person, those in remote, and possible facilitators who manage the virtual space in real time (Jeijon \& Lundgren, 2019). For example, hybrid class teachers lament that the physical constraint of cameras in the hybrid environment decreases teaching style flexibility and promotes lecture-style classes. Furthermore, it reduces the teachers' control on interactions with and between the students, as well as between the students and their environment, all of which are crucial aspects for learning.

\section{Physical and virtual spaces throughout the pandemic}

Although Massive Open Online Courses (MOOCs) and fully online teaching platforms have existed for several years, before the pandemic, virtual spaces played a mostly supporting role in higher education, almost invariably associated with in-person lectures, labs, and/or seminars. The borderline to the realm of exclusively online teaching was crossed only by those students who did so out of personal necessity and by those teachers (probably a minority) who were enthusiastic 
and curious enough to experiment with different techniques and pedagogies on a voluntary basis.

As the Covid-19 pandemic struck, educational institutions were forced to swiftly adapt to everchanging social distancing measures and limitations on the frequentation of physical learning spaces. During the first lockdown of spring 2020, British universities witnessed an unprecedented and abrupt shift towards virtual spaces for every aspect of teaching, from lecture delivery to assessment and support (Ortiz, 2020; Yan, 2020; Mondol \& Mohiuddin, 2020). As uncertainty persisted, a number of high-profile British institutions decided to hold their lectures completely online during the following academic year (PA Media, 2020). Some universities opted for a mixed approach and allowed partial reopenings during the Autumn term for PGR labs and seminar teaching (Toms \&

Karageorgi, 2020). To comply with social distancing rules, a 2-meter distance rule between students' desks and between tutors and students was enforced and, consequently, class sizes were reduced. The steep rise in Covid-19 cases during winter led to a second lockdown, which saw a return to fully online teaching and learning.

In the meantime, online teaching platforms were upgraded. New features were constantly added and old ones improved. For example, by the time the second winter lockdown hit, Microsoft Teams had introduced break-out rooms for small group discussion (Microsoft Teams team, 2020) and more intuitive and inclusive interaction options (Spataro, 2020). Hence, throughout the pandemic, both physical and virtual learning spaces witnessed radical and frequent changes in their material aspects, affordances, and interactivity.

\section{My personal experience of physical space before the pandemic}

During my pre-pandemic PGR teaching experience in labs and seminars in Computer Science, I made very little use of virtual spaces for offering direct support, and used online platforms only to provide written feedback. My relation with physical space was shaped by two prevalent forms of interactions between me and the students: the "one-to-all communication", when I addressed all students at once for essential directions, and the "one-to-one" or "one-to-few support", when I checked whether individual students or small groups of students sitting in proximity to one another were on-task or needed individualised clarifications. In spatial terms, this brought me to either occupy the front position in the seminar room or lab, next to the whiteboard, or to walk around the desks and stand near students to create bubble-like environments with one or few of them within which they could express their doubts more privately and comfortably.

My usage of space could not escape the influence of the physical layout of the rooms themselves (Smith, 2017; Brooks, 2012): computer labs, for example, in which a single central corridor is flanked by narrow and long rows of immobile desks, promoted individual work or very small group interactions, hindering communication to and between larger groups. Nevertheless, my usage of space was primarily informed by my own experience of seminars as a Mathematics student in English and French universities. These privileged, respectively, on-demand one-to-one support, and lecture-style seminars in which the teacher and the students interacted openly in front of the class through the physical support of the blackboard. These two approaches can be considered signature pedagogies for Mathematical seminars. They effectively promote the development of individual problem-solving skills, the acquisition of specific terminology, and the appreciation for clarity and conciseness in argument construction which constitute the core of university-level Mathematical learning 
and assessment. That said, these individualcentred approaches are less effective in preparing for research and project collaborations in small groups, which I have found to be frequent in both academic and industrial work environments after graduation. Finally, my usage of space was the result of negotiations with the students, who were often reluctant to communicate their doubts publicly and solve problems at the board, reflecting the principle that learning space is negotiable and is designed via the interaction with the participants (Leijon \& Lundgren, 2019).

\section{Personal experience through-out the pandemic}

During the first lockdown, I did not have the chance to teach. As relevant scholarly research on the dynamics of virtual spaces remained quite limited, my best sources of information were the experiences of some of my colleagues who had to adapt to using virtual tools. Perhaps the most interesting observation I heard from them is that the complex interactions that were mediated through physical space could be reproduced in virtual spaces, at least in part, through clever use of time. For example, walking around the desks could be substituted by asking students to submit their results regularly during the class and allowing extra time for questions after the class.

I first returned to teach during the first term of the 2020/2021 academic year, when seminars happened in person, but social distancing rules were imposed. I soon discovered, though, that my "one-to-one" and "one-to-few support" approach became much more difficult to implement as my movements were constrained to a small area around the whiteboard, in the front of the class, which meant that I could no longer create individualised spaces for students to ask questions. Instead, students would have to raise their doubts publicly and, as a consequence, very few did. A small number would wait until the end of the class to ask me questions, but my overall perception was that my classes had become considerably less interactive. More creative layouts and small group cooperation were, de facto, impeded by the social distancing rules, as seating was fixed and students did not naturally communicate to one another given the distance and impossibility to comfortably share written notes. To preserve the efficacy of my classes, I had to rely on the virtual realm, which I used to solve individual doubts and to provide much more detailed feedback on students' work, but this increased noticeably the time burden on my side.

During the second lockdown, all of my seminars happened online. My attempts to directly transpose the above-described signature pedagogies to the virtual realm proved unsatisfactory and frustrating. The efficacy of one-to-all explanations was strongly diminished by the lack of visual and physical cues from the students, which in the past I had found very helpful for gauging understanding and deciding whom to spur. I gave one-to-one support through private chats, sending screenshots instead of writing on copybooks, but it proved to be far less effective, as well as rather time consuming.

Major improvement happened through implementing an almost complete overhaul of the activities in class. I switched to a model based on small group cooperation and mutual support. After briefly introducing the intended outcome of the seminar, I divided students into groups, using the breakout room function afforded by Microsoft Teams. Each group was provided with a whiteboard that students could use for collaborating. I would visit each room for several minutes, just as I would normally move around desks, to ask students to express their doubts. Instead of providing direct help, though, I would encourage students to support each other after the doubts had been formalised. Finally, I would reunite the class to provide solutions to the exercises and make remarks based on what I had heard in the breakout rooms. 
The small-group-based approach proved generally satisfactory, as measured by perceived participation and informal feedback provided by students. The most noticeable negative aspect raised by students was the fact that whiteboards in the breakout rooms would disappear once the breakout rooms were closed, so that any work they had not saved as I closed the rooms would be lost. This problem was easily solved by announcing closures in advance and taking screenshots. A major difference between breakout rooms and spontaneous group formation was that students would have less choice to cooperate with people they knew (as opposed to choosing one's companions by sitting next to them in a classroom). On rare occasions, this would create a group of shy students who would prefer not to collaborate, but this also meant a more equitable rearranging of groups in the long run, and I noticed a clear increase in collaboration as students got used to the system and got to know each other.

Another difference was that as a seminar tutor, I had much more control on group sizes, which I could tailor and adjust according to the activity. However, in practice, size was often dictated by the number of people in attendance and by practical limits on the number of groups I was able to satisfactorily supervise at the same time. In my case, I found four groups of up to six students to be the ideal size, after attempts with a larger number of smaller groups showed the impossibility of spending enough time in each virtual room and giving the students the time to formulate their questions without the fear of leaving other groups behind.

\section{Reflection on the usage of physical and virtual space}

Reaching awareness on one's usage of physical and virtual space and its impact on teaching is only helpful if such awareness is critically challenged and channelled towards practical improvements. As the Covid-19 outbreak continues to cast uncertainty on the nature of seminars and labs in the next academic year, a natural question to ask myself is how I could implement the above reflections, observations, and research-based suggestions, should teaching take place, partially or totally, in the virtual realm.

I found it surprising that I, as a rather conservative seminar tutor, reacted much more positively to teaching virtual classes than to teaching face-to-face classes when social distancing constraints were imposed. The forced switch to virtual spaces meant that I had no choice but to familiarise myself with their features. Perhaps, more importantly, it provided a unique incentive to break my routinised practice, as experimentation became a strict necessity. I concluded that making use of small-group-focused teaching style and layouts, physical and virtual, is an entirely suitable option for Mathematical courses, even though I had never encountered them in my experience as a student.

\section{Conclusion}

The role of physical and virtual space in teaching and learning is vast and multifaceted, and research is only now beginning to unfold its full implications. Whether or not the Covid19 pandemic will once again force universities to a complete or partial shift to online teaching and learning, this outbreak, having deprived us of a resource we so frequently give for granted, provides a priceless occasion to ponder and challenge the way we make use of it. Reflection and continuous professional development are necessary steps, but achieving best practice requires time and a certain dose of experimentation, and inevitably - mistakes.

\section{Making sure the students are made} aware of the role that space, both physical and virtual, has played in their education and of the challenges teachers face because of the mutability of its affordances, is essential to have their full cooperation and achieve the best results. Shifting control from the teacher to the students may turn out to be a fruitful 
experiment. After all, if physical spaces are designed and made meaningful via negotiations and interaction, why should it be otherwise for virtual ones?

\section{References}

Amedeo, D., Golledge, R.G. and Stimson, R.J., 2008. Person-environment-behavior research: Investigating activities and experiences in spaces and environments. Guilford Press.

Baepler, P., Walker, J.D., Brooks, D.C., Saichaie, K. and Petersen, C.I., 2016. A guide to teaching in the active learning classroom: History, research, and practice. Stylus Publishing, LLC.

Brooks, D.C., 2012. Space and consequences: The impact of different formal learning spaces on instructor and student behavior. Journal of Learning Spaces, 1(2), p.n2.

Exley, K. and Dennick, R., 2004. Small group teaching: Tutorials, seminars and beyond. Routledge.

Leijon, M. and Lundgren, B., 2019. Connecting physical and virtual spaces in a HyFlex pedagogic model with a focus on teacher interaction. Journal of Learning Spaces; 1, 8.

Microsoft Teams team, 2020. Breakout rooms generally available today in Microsoft Teams. [Online] 9 Dec. [Accessed 16 July 2021].

Available from:

https://techcommunity.microsoft.com/t5/micro soft-teams-blog/breakout-rooms-generallyavailable-today-in-microsoft-teams/ba$\mathrm{p} / 1968481$

Monahan, T., 2002. Flexible space \& built pedagogy: Emerging IT embodiments.

Mondol, M.S. and Mohiuddin, M.G., 2020. Confronting Covid-19 with a Paradigm Shift in Teaching and Learning: A Study on Online Classes. International Journal of Social, Political and Economic Research, 7(2), pp.231247.

Norman, D., 2002. The design of everyday things (pp. 1-218)

Oliver Toms, Nicole Karageorgi, 2020.

Warwick students for online lectures, but still want some in-person teaching. The Boar. [Online]. 28 Sep. [Accessed 16 July 2021]. Available from:

https://theboar.org/2020/09/warwick-studentsfor-online-lectures-but-still-want-some-inperson-teaching/

Ortiz, P.A., 2020. Teaching in the time of COVID-19. Biochemistry and Molecular Biology Education.

PA Media, 2020. Cambridge University moves all lectures online until summer 2021. The Guardian. [Online]. 19 May. [Accessed 09 July 2020]. Available from:

https://www.theguardian.com/uknews/2020/may/19/cambridge-universitymoves-all-lectures-online-until-summer-2021

Parsons, C.S., 2016. " Space and Consequences": The Influence of the Roundtable Classroom Design on Student Dialogue. Journal of Learning Spaces, 5(2), pp.15-25.

Rands, M.L. and Gansemer-Topf, A.M., 2017. The room itself is active: How classroom design impacts student engagement. Journal of Learning Spaces, 6(1), p.26.

Smith, C., 2017. The Influence of Hierarchy and Layout Geometry in the Design of Learning Spaces. Journal of Learning Spaces, 6(3), pp.59-67.

Spataro, J., 2020. New Microsoft Teams features and tips to make virtual interactions and meetings more natural, engaging and human [Online] 9 Jul. [Accessed 16 July 2021]. Available from: https://news.microsoft.com/enmy/2020/07/09/new-microsoft-teams-featuresand-tips-to-make-virtual-interactions-morenatural-engaging-and-human/

White, D.S. and Le Cornu, A., 2011. Visitors and Residents: A new typology for online engagement. First monday.

Yan, Z., 2020. Unprecedented pandemic, unprecedented shift, and unprecedented 
Journal of PGR Pedagogic Practice

opportunity. Human Behavior and Emerging

Technologies, 2(2), pp.110-112.

To cite this article: Matteo Mazzamurro. 2021. "In search of lost space: the changing affordances of physical and virtual teaching spaces during the pandemic." Journal of PGR Pedagogic Practice, 1, 25-30. Available at: [url] 